\title{
Reconstructed Empiricism
}

\author{
Finnur Dellsén
}

Penultimate draft; please cite the article in Acta Analytica

\begin{abstract}
According to Bas van Fraassen, scientific realists and anti-realists disagree about whether accepting a scientific theory involves believing that the theory is true. On van Fraassen's own anti-realist empiricist position, accepting a theory involves believing only that the theory is correct in its claims about observable aspects of the world. However, a number of philosophers have argued that acceptance and belief cannot be distinguished and thus that the debate is either confused or trivially settled in favor of the realist. In addition, another set of philosophers have argued that van Fraassen's empiricist position appeals to an unmotivated distinction between observable and unobservable aspects of the world. This paper aims to reconstruct a van Fraassen-style empiricism about scientific acceptance that avoids these two objections - reconstructed empiricism.
\end{abstract}

\section{INTRODUCTION}

A popular quip has it that there are at least as many versions of scientific realism as there are scientific realists and anti-realists combined. One widelydiscussed aspect of the scientific realism debate, influentially discussed in Bas van Fraassen's The Scientific Image (1980), concerns what kind of epistemic

\footnotetext{
${ }^{1}$ To be sure, van Fraassen also conceives of realism and anti-realism in terms of the aim of science, understood as the criteria for success in the scientific enterprise. However, I shall leave that part of the debate to one side in most of this paper, focusing instead on the part that concerns scientific acceptance.
} 
attitude is involved in the acceptance of a scientific theory, where realists and anti-realists are seen as disagreeing about whether that attitude extends to the unobservable entities posited by scientific theories. ${ }^{1}$ According to the realist position defined by van Fraassen, "acceptance of a scientific theory involves the belief that it is true" (van Fraassen, 1980, 12). By contrast, van Fraassen's own anti-realism, constructive empiricism, holds that "acceptance of a theory involves as belief only that it is empirically adequate" (van Fraassen, 1980, 8), where a theory is "empirically adequate" roughly just in case it is correct in its claims about the observable aspects of the world. ${ }^{2}$

While this conception of scientific realism and anti-realism has received its fair share of attention, it has proven hard to get a grip on exactly what the realist and anti-realist are meant to be disagreeing about. Indeed, some philosophers have argued that there is no conceptual distinction between accepting a theory and believing it to be true, and thus that the debate is either confused or trivially settled in favor of the realist. Either way, this spells disaster for van Fraassen's constructive empiricism, since the position is either trivially false or part of a debate that is itself confused. (Blackburn, 1984, 2002; Mitchell, 1988; Horwich, 1991; Teller, 2001) Another major objection to constructive empiricism is that its reliance on the distinction between observable and unobservable entities is unmotivated. In support of this, realists often point out that it is hard to see what is in principle more problematic about forming beliefs concerning unobservable entities than forming beliefs about unobserved-but-observable entities. (Railton, 1989; Rosen, 1994; Sober, 1985, 1993; Churchland, 1985; Psillos, 1996; AlspectorKelly, 2001; Kitcher, 2001; Ladyman, 2007)

This paper aims to reconstruct a van Fraassen-style empiricism about scientific acceptance that avoids these two objections. Two things should be clear from the outset: First, the position I will defend is not van Fraassen's own position. Rather, it is a somewhat more modest position that nevertheless captures

\footnotetext{
${ }^{2}$ This rough characterization of empirical adequacy will do for the purposes of this paper. For a much more precise characterization, see (van Fraassen, 1980, chapter 3).
} 
what I take to be the basic idea behind constructive empiricism, i.e. roughly that acceptance "answers to" empirical adequacy as opposed to truth. Second, I will not attempt to provide a positive argument for this position. Rather, I will construct an empiricist position that avoids what I take to be the two most serious objections to constructive empiricism. Thus I will in effect argue that one may be a particular kind of empiricist about acceptance, not that one should be such an empiricist. ${ }^{3}$

The plan of the paper is as follows. The first part of the paper argues for a reconstruction of van Fraassen's empiricist position in light of the objection that acceptance and belief are conceptually identical. Roughly, the argument will be that although acceptance and belief can be separated given a plausible definition of "acceptance", this will not be of any particular help to the empiricist since it will mean that acceptance of a theory does not even involve the belief that the theory is empirically adequate. (Section 2.) Accordingly, I suggest a weaker formulation of realism and empiricism on which the issue concerns the normative connection between acceptance and belief in a theory's empirical adequacy. (Section 3.) When the debate has been reconstructed in this way, I argue that an empiricist position much like van Fraassen's constructive empiricism remains an open possibility. (Section 4.) In the second part of the paper, I go on to argue that the distinction between observable and unobservable entities is not unmotivated given this conception of the debate, roughly because of the role accepted theories play in empirical predictions. (Section 5.) I thus conclude that a reconstructed empiricist position, construed as positing a normative connection between acceptance and belief in a theory's empirical adequacy, avoids two of the most serious challenges to an empiricist view of scientific acceptance. (Section 6.)

\footnotetext{
${ }^{3}$ This is in line with van Fraassen's own defense of constructive empiricism, since van Fraassen (1980) offers little if anything in terms of direct positive arguments for his position. Instead, as Rosen (1994, 157-8) notes, van Fraassen's aim seems to be to show that constructive empiricism is a permissible stance, one that is not in conflict with the rationality of science.
} 


\section{Distinguishing Acceptance And Belief}

On van Fraassen's conception of the scientific realism debate, the realist and the anti-realist are both making claims about the relationship between acceptance and belief. It is clear enough what the relationship is supposed to be: In saying that acceptance involves some belief or other, the idea is that the belief in question is necessary for acceptance. So according to van Fraassen, the realist position can be characterized as holding that one accepts a scientific theory $T$ only if one believes that $T$ is true. An anti-realist, by contrast, denies that acceptance of a theory requires that one believe that the theory is true - although a constructive empiricist such as van Fraassen grants that a restricted belief is required for acceptance, namely the belief that $T$ is empirically adequate.

As things stand, however, it is unclear what concept is denoted by the term "acceptance", and so it is unclear what exactly the realist and the constructive empiricist are disagreeing about. It is clear, however, that realism and empiricism are not meant to offer stipulative definitions of "acceptance". Rather, as Rosen (1994, 145) points out, van Fraassen holds that acceptance is "a phenomenon of scientific inquiry" (van Fraassen, 1980, 12) and thus something that both the realist and empiricist can locate in scientific practice even though they disagree about the belief involved therein. Unfortunately, however, van Fraassen never explicitly defined "acceptance" (or "belief" for that matter), despite its central role in his characterizations of scientific realism and constructive empiricism, making it hard to evaluate both the empiricist view he outlines and the realist view he rejects.

Although van Fraassen does not define "acceptance", he makes clear that acceptance of a theory $T$ involves a robust commitment to $T$ for various scientific purposes. For example, accepting $T$ involves relying on $T$ in making predictions and appealing to $T$ in one's explanations (van Fraassen, 1980, $12 \&$ 151-2). ${ }^{4}$ This

\footnotetext{
${ }^{4}$ See also (van Fraassen, 2002, 90).
} 
has led a number of philosophers to argue that the concept of acceptance collapses into the concept of belief (Blackburn, 1984, 2002; Melchert, 1985; Mitchell, 1988; Horwich, 1991). Simplifying somewhat, their argument rests on the claim that to believe a proposition just is to be disposed to behave in certain ways, which is also what it is to accept the proposition. Similarly, Teller (2001) has argued that what van van Fraassen (1980) calls belief is really just acceptance. On Teller's view, it is not acceptance that collapses into belief, but instead belief that collapses into acceptance (Teller, 2001, 139-142). If either of these arguments is sound, constructive empiricism (and indeed any anti-realist view of scientific acceptance) is incoherent: One couldn't possibly accept $T$ without believing $T$, and so van Fraassen's antirealist position would simply be confused. Moreover, scientific realism would be analytically true, which would no doubt come as a surprise to many realists. No wonder Blackburn concludes that the issue of scientific realism "has not been clearly posed". (Blackburn, 2002, 111)

The objections of Blackburn, Melchert, Mitchell, Horwich, and Teller can be seen as creating troubles for both realists and anti-realists about scientific acceptance. For realists, the problem is that the realist account of the relationship between acceptance and belief threatens to be analytically true and thus trivial. For anti-realists such as van Fraassen, the problem is even more serious, since their accounts would be analytically false. Thus both parties to the debate should be motivated to find a definition of "acceptance" that does not make acceptance of a theory conceptually identical to belief in the theory's truth. Since van Fraassen himself does not offer a definition, we are forced to look elsewhere. Fortunately, several other philosophers have defined terms which are meant to be contrasted with "belief", and which they refer to as "acceptance". One such definition stands out as particularly congenial to the debate over scientific realism. ${ }^{5}$

This definition is originally due to L. Jonathan Cohen $(1989,1992)$, although

\footnotetext{
${ }^{5}$ For some of the other definitions of "acceptance" along the same lines, see (Alston, 1996), (Lehrer, 1979), (Kaplan, 1981b,a, 1995), (Bratman, 1992), (Maher, 1993), (Lance, 1995), and (Velleman, 2000).
} 
it has recently been applied to the realism debate about scientific acceptance by Paul Dicken (2010). In An Essay on Belief and Acceptance, Cohen defines "acceptance," and contrasts it with "belief", as follows:

[... belief that $p$ is a disposition, when one is attending to issues raised, or items referred to, by the proposition that $p$, normally to feel it true that $p$ and false that not-p, whether or not one is willing to act, speak, or reason accordingly. But to accept the proposition or rule of inference that $p$ is to treat it as given that $p$. More precisely, to accept that $p$ is to have or adopt a policy of deeming, positing, or postulating that $p$ - i.e. of including that proposition or rule among one's premisses for deciding what to do or think in a particular context, whether or not one feels it to be true that $p$. (Cohen, 1992,

4)

So, on Cohen's definition, to accept a proposition is to have a policy of treating it as given in a particular context, whereas to believe something is to have a disposition to feel it to be true. While acceptance and belief may normally coincide on this definition, they can also come apart. For example, a defense attorney may accept that her client is innocent in the context of her legal work even though she does not believe it, since she may adopt a policy of treating her client as innocent despite her feeling (perhaps strongly) that the client must be guilty. One important difference between acceptance and belief on Cohen's account, emphasized by Dicken (2010, 157-167), is the extent to which they are under our control: The lawyer may simply decide to treat it as given that her client is innocent, whereas it will be more difficult (and perhaps even impossible)

\footnotetext{
${ }^{6}$ That beliefs are involuntary in this way was influentially argued by Williams (1973). In contrast to Dicken (2010, 161-167), I will not assume here, however, that beliefs are completely involuntary - it may be possible, with effort, to induce in oneself certain beliefs in certain circumstances. This does not eliminate the distinction between acceptance and belief with respect to the extent to which they are under our control, since acceptance would still be voluntary in a much more straightforward way. After all, there is no special cognitive effort required to adopt a policy of treating propositions as given in a particular context. (See further discussion of this point in footnote 11.)
} 
for her to decide to feel that this is true. ${ }^{6}$

Now, Cohen's definition is congenial to the scientific realism debate because there is a clear sense in which scientists who use certain theories in their scientific work have a policy of treating those theories as given in a scientific context (much like the lawyer has a policy of treating it as given that her client is innocent in the context of her legal work). So, following Cohen's definition, we can say that for a scientist qua scientist to accept a theory $T$ is for the scientist to have or adopt a policy of treating $T$ as given in a scientific context. Note that acceptance in this sense can be both full and partial, since the corresponding policy can be such that one treats $T$ as given for certain scientific purposes and not others. For example, one may treat Newtonian mechanics as given for the purposes of making certain basic calculations even though one does not treat it as given when calculating, say, a star's parallax. However, unless otherwise stated, I will in this paper be discussing full acceptance in a scientific context, i.e. the treating of a theory as given for all scientific purposes (when the theory is applicable at all). Thus, from now one, "acceptance" refers to full acceptance in a scientific context. ${ }^{7}$

Of course, this definition is not particularly informative unless we specify what is involved in treating a theory as given in a scientific context. Without attempting to provide a full characterization, it is clear that this will include using the theory for various scientific purposes, e.g. as the basis for empirical predictions, as premises in one's explanations, and as a guides in further theory construction. This would make sense of van Fraassen's claim that acceptance is "a phenomenon of scientific inquiry" (van Fraassen, 1980, 12), since these activities seem to be part and parcel of what it is to do science. It may of course be argued that some of these activities are not really part of science (as some empiricists

\footnotetext{
${ }^{7}$ This might very well mean that full acceptance is relatively rare in science, since most theories arguably involve approximations and idealizations in such a way that working scientists would not be prepared to rely on them for all scientific purposes in which the theory is relevant at all. Nevertheless, since van Fraassen an others participants in the debate seem to be primarily concerned with full acceptance, it is full acceptance which I shall be concerned with here. Besides, one could presumably give realist and anti-realist accounts of partial acceptance by modifying the accounts of full acceptance that are discussed here (though I shall not attempt to do so in this paper).
} 
have argued that explaining is not involved in doing science), ${ }^{8}$ and thus that they are not part of the scientific context in which an accepted theory is treated as given. However, all that is required for there to be such a thing as acceptance in a scientific context is that there be some such scientific activities in which a theory can be treated as given.

Now, Dicken rightly emphasizes that on a definition like Cohen's, acceptance and belief are "entirely distinct" attitudes in that one can accept a theory that one does not believe to be true (Dicken, 2010, 153-157). ${ }^{9}$ Dicken is surely right on this point. After all, accepting a theory is a matter of having a policy of using that theory for some scientific purposes (e.g. to predict, explain, or guide theory construction), whereas believing a theory is a matter of having a disposition to feel it to be true. Clearly, one can lack the feeling that a particular theory is true and yet have adopted a policy of using the theory in predictions, explanations, guidance to theory construction, and so forth. Of course, it may well be true that most of what one accepts one also believes to be true, but if acceptance is having a policy for using the theory in certain contexts while belief is a disposition to have a particular feeling towards the theory, then the two attitudes can clearly come apart.

However, while this distinction between acceptance and belief avoids the objection that acceptance is identical to belief (and thus make constructive empiricism coherent), it also raises a different but equally damning problem for constructive empiricism. If acceptance and belief are indeed entirely distinct,

\footnotetext{
${ }^{8}$ For example, the idealist-positivist Karl Pearson wrote in the third edition of The Grammar of Science:

Nobody believes now that science explains anything; we all look upon it as a shorthand description, as an economy of thought. (Pearson, 1911, xi)

Pierre Duhem seems to have advocated a similar view:

A physical theory is not an explanation. It is a system of mathematical propositions, deduced from a small number of principles, which aim to represent as simply, as completely, and as exactly as possible a set of experimental laws. (Duhem, $1982,19)$

${ }^{9}$ As Dicken $(2010,157)$ points out, one can also believe a theory that one does not accept, although this possibility will play no role in what follows.
} 
then one can accept a theory that one does not even believe to be empirically adequate, since having a policy of using a theory for some particular purposes clearly does not entail that one believes the theory to be empirically adequate. ${ }^{10}$ To bring this out, consider a deeply religious evolutionary biologist - Alyssa who uses Darwin's theory of natural selection in her practice as a scientist, e.g. by using it as a premise in her explanations and predictions. In other words, Alyssa has adopted a policy of treating the theory of natural selection as given in the context of her scientific work, and thus accepts it. However, suppose also that because of her religious convictions, Alyssa just cannot bring herself to believe any part of Darwin's theory - she is psychologically unable to do so. Alyssa may even realize that she ought to believe at least some parts of the theory, perhaps because (she thinks) the evidence speaks overwhelmingly in its favor. Yet Alyssa does not believe (to any degree) that the theory is even empirically adequate. Since cases like this are clearly possible (and plausibly actual in some instances), acceptance of a theory need not involve the belief that the theory is empirically adequate. $^{11}$

This leaves us with the following conundrum. Given the independently plausible Cohen-Dicken distinction between acceptance and belief, acceptance of a theory clearly does not involve believing that the theory is empirically adequate. Nor does it involve the belief that the accepted theory is true. So, on van Fraassen's conception of the debate about scientific acceptance, both constructive empiricism would simply be false - and the same goes for scientific realism. Instead we

\footnotetext{
${ }^{10}$ Indeed, something like this is suggested by Cohen himself in a brief mention of van Fraassen's views (Cohen, 1992, 89).

${ }^{11}$ It may be noted that this holds even if one accepts a strict functionalist view of belief (as Horwich (1991) does explicitly), since the functional roles of acceptance and belief in empirical adequacy can come apart on Cohen's definition. To see this, imagine someone - Bertie - who is just like Alyssa except that he believes Darwin's theory of natural selection to be empirically adequate in addition to accepting it. In contrast to Alyssa, Bertie will function outside of a scientific context as someone who believes that the theory is empirically adequate. So, for example, Bertie will normally be inclined to assert that Darwin's theory of natural selection makes correct prediction about observable phenomena in his day-to-day interactions outside of a scientific context in a way that Alyssa will not be inclined to do (since she does not believe that the theory is empirically adequate). So scientific acceptance and belief in a theory's empirical adequacy will clearly differ in their functional outputs.
} 
would have a particularly extreme form of anti-realism, one according to which neither kind of belief is necessary for acceptance. Clearly, then, the Cohen-Dicken distinction by itself wouldn't help either the realist or the empiricist to formulate the debate in which they mean to engage, since both positions now seem completely wrongheaded. In particular, pace Dicken (2010, e.g. 146-148 \& 210211), we haven't then found a way to characterize realism and its alternatives in a way that leaves room for a defensible empiricist position in the style of van Fraassen's constructive empiricism. The next two sections propose a way out of this situation.

\section{Realism: Reconstructing the Debate}

According to van Fraassen's conception of the realism debate, a realist thinks there is some intimate connection between accepting a theory and believing that the theory is true (and an empiricist thinks there is a similar connection between accepting a theory and believing that the theory is empirically adequate). The upshot of the previous section is that, given the Cohen-Dicken distinction, this connection between acceptance and belief cannot be about what kind of belief is necessary for acceptance, since one can clearly accept a theory without believing that it is either true or empirically adequate. However, this section argues that

\footnotetext{
Moreover, these two states will differ also in their functional inputs. This is because it is relatively straightforward to accept at will, whereas it is more difficult, and perhaps even impossible, to believe at will. Consider how straightforward it is to decide to adopt a policy of using a theory in one's scientific endeavors even if one does not find it plausible that the theory is empirically adequate. Such a decision would be on par with deciding to adopt other policies, e.g. to become a vegetarian or to exercise three times a week. By contrast, it would require much more cognitive effort to make oneself believe that such a theory is empirically adequate, i.e. to feel that the theory is empirically adequate. To induce in oneself a feeling of this sort would seem to require some special feat that most of us are unable to perform, at least most of the time and for most propositions. Indeed, many philosophers follow Williams (1973) in arguing that it is impossible to have direct control over our beliefs (and that applies to beliefs about which theories are empirically adequate just as much as it applies to beliefs about which theories are true). At any rate, if belief is under any kind of voluntary control, it is clearly less direct than the sort of control we have over whether we accept a theory, i.e. whether to adopt a policy of treating the theory as given in some context. Thus it is clear that acceptance and belief - including in particular belief in empirical adequacy - differ functionally not just with regard to their outputs, but also with regard to their functional inputs.
} 
the realism debate can still be understood as concerning a connection between acceptance and belief, albeit a normative rather than necessary connection. In this section, I thus define a type of realism about acceptance; in the next section, I define the corresponding empiricist position about acceptance.

My suggestion is that realism about scientific acceptance should be seen as holding that acceptance "involves" belief in the sense that it is permissible to accept a theory in a scientific context only if it is permissible to believe that it is true. Put differently:

$\left(\mathrm{R}^{*}\right)$ A theory $T$ should only be accepted in a scientific context if it is permissible to believe that $T$ is true. ${ }^{12}$

Although $\left(\mathrm{R}^{*}\right)$ is not the definition of realism about acceptance given by van Fraassen - happily, given the problematic nature of that definition - there is a clear sense in which it captures the kernel of truth in van Fraassen's suggestion that scientific realism holds that accepting a theory involves believing it to be true. To see this, note that if accepting a theory $T$ did involve believing that $T$ is true, then surely one should only accept $T$ if believing $T$ (which would be involved in accepting it) is permissible. ${ }^{13}$ Given this conditional, van Fraassen's conception of realism straightforwardly implies $\left(\mathrm{R}^{*}\right)$. The implication does not go the other way, however, for one could commit to the claim that one should only accept what it's permissible to believe is true, and yet deny in the same voice that one's acceptance of $T$ entails that one believes that $T$ is true (as is argued above). So, in sum, $\left(\mathrm{R}^{*}\right)$ is a more modest conception of realism that

\footnotetext{
${ }^{12}$ A slightly weaker form of $\left(\mathrm{R}^{*}\right)$ replaces "true" with "at least approximately true". Nothing in what follows depends on which version of $\left(\mathrm{R}^{*}\right)$ one adopts, so for simplicity's sake I shall stick with this formulation of $\left(\mathrm{R}^{*}\right)$.

${ }^{13}$ This follows from a general principle: If $\phi$-ing involves $\psi$-ing, then one should only $\phi$ if it is permissible to $\psi$. This principle seems to me obviously and transparently true. However, in case you're not convinced already, consider the following argument for it. Suppose $\phi$-ing involves $\psi$ ing. Now suppose that $\psi$-ing is not permissible. Then there is no permissible way to $\phi$, because all ways of $\phi$-ing involve $\psi$-ing, which is ex hypothesi not permissible. Put differently, every possible $\phi$-ing is impermissible. But that is just to say that $\phi$-ing is itself impermissible. So, if $\phi$-ing involves $\psi$-ing, then $\phi$-ing is impermissible if $\psi$-ing is impermissible. This is logically equivalent to the principle.
} 
nevertheless captures van Fraassen's basic idea that realism holds that there is some intimate connection between the acceptance of a theory and the belief that it is true.

So $\left(\mathrm{R}^{*}\right)$ is the definition of realism about scientific acceptance that I propose as a replacement of van Fraassen's definition in light of the problems it encountered. As we shall see in the next section, it will also allow us to define a defensible anti-realist position in the style of van Fraassen's constructive empiricism. Before I do that, however, I want to elaborate on this definition in a few ways. First of all, note that $\left(\mathrm{R}^{*}\right)$ is compatible with there being other normative requirements on scientific acceptance besides that specified in $\left(\mathrm{R}^{*}\right)$. Thus a proponent of $\left(\mathrm{R}^{*}\right)$ - a realist - may say, for example, that theories should only be accepted if they are reasonably simple and well-managed (even if she thinks these features are merely pragmatic as opposed to epistemic virtues of the theory). After all, accepting very complicated or unwieldy theories may be a bad idea from a practical standpoint, because calculations and derivations with such theories would be unnecessarily difficult. To acknowledge such "pragmatic" requirements on acceptance does not make one an anti-realist on this definition as long as one also thinks that acceptance is governed by a normative requirement that it be permissible to believe the accepted theory.

Second, I want to make an important point concerning permissible belief that will allow us to reformulate $\left(\mathrm{R}^{*}\right)$. According to a widespread view, sometimes called evidentialism, a belief is permissible just in case the believed proposition is evidentially supported. Somewhat more precisely:

(B) It is permissible to believe that $p$ is true if and only if $p$ 's truth is supported by the available evidence.

One may want to spell out (B) in various ways, e.g. by specifying whether it applies to full beliefs and/or credences (degrees of belief), and what precisely it is for available evidence to support the truth of a proposition. But none of that will be important in what follows. What's important is only that according to (B), believing $p$ comes with a normative requirement in terms of the evidential 
support for $p$ being true. This can be contrasted with various other attitudes one might have towards a proposition, e.g. hoping and imagining, which clearly do not carry with them the same normative requirement of evidential support.

Now, importantly, to say that belief is governed by the normative requirement described in (B) should not be taken to imply that this requirement cannot be overridden or outweighed in a particular case. In other words, (B) should be understood as specifying a pro tanto obligation with respect to belief. To see this, suppose someone threatens to murder your best friend unless you believe that the earth is flat. There is clearly a sense in which believing that the earth is flat is permissible in such a case, even though doing so would involve believing an unjustified falsehood. Nevertheless, there is also a sense in which you have failed as a believer if you manage to convince yourself that the earth is flat. In this respect the norms of belief are like the rules of a game, e.g. the rule in chess that says that the bishop should only be moved diagonally: The fact that one could have excellent prudential or moral reasons to move one's bishop in a different manner does not show that the rule fails to apply in a given case. Similarly, (B) may be overridden or outweighed in a particular case, e.g. by moral or prudential considerations, but that does not mean that the requirement does not apply.

Although I do accept (B) thus understood, my aim is not to argue for it here. Rather, what I want to note is that given $(B),\left(R^{*}\right)$ is equivalent to the claim that one should only accept a theory if it is supported by the available evidence. So those of us who accept (B) can define the realist thesis in terms of evidential support as follows:

(R) A theory $T$ should only be accepted in a scientific context if $T$ 's truth is supported by the available evidence.

Of course, (R) should be understood in a similar way as (B), i.e. as specifying a pro tanto obligation that may be outweighed or overruled in particular cases. Understood in that way, there may be cases in which one should, in some natural sense, accept a theory which isn't supported by the available evidence - but then only when there is a stronger or overriding non-epistemic reason to do so. 
It seems to me that $(\mathrm{R})$ is a more natural and informative way of stating the realist account of scientific acceptance, given that it brings out the epistemic commitment of scientific realism in a way that $\left(\mathrm{R}^{*}\right)$ does not. In particular, note that (R) stands opposed to various skeptical arguments which conclude that scientific theories concerning observables are false or unjustified. Consider, for example, the well-known underdetermination argument (UA), which concludes (roughly) that it is not reasonable to believe any scientific theories about unobservables to be true, because for any such theory there is (according to the argument) a rival theory that is at least as well supported by one's evidence. Why is this argument generally considered to be a threat to scientific realism? I suggest it is at least in part because the conclusion of UA conflicts with $(R)$ given the claim that it is permissible for scientists to accept their most successful theories. That is, the following three claims form an inconsistent triad:

(i) A theory $T$ should only be accepted in a scientific context if $T$ 's truth is supported by the available evidence. [(R)]

(ii) It is not the case that the truth of our most successful scientific theories is supported by the available evidence. [Conclusion of UA.]

(iii) It is permissible to accept in scientific context our most successful scientific theories.

Clearly, no genuine realist would reject (iii) (and neither would most anti-realists). If realism is also committed to (i), as I'm suggesting, then it follows that realists must reject (ii), the conclusion of UA. However, if realism is not committed to (i), then it's not clear why realists couldn't simply embrace (ii). Of course, one might think that rejecting (ii) is definitional of what it is to be a scientific realist, but given $(\mathrm{R})$ we can give a principled reason why realists must reject UA. So (R) fits very well with the plausible thought that skeptical arguments like UA are distinctively anti-realist arguments in a way that $\left(\mathrm{R}^{*}\right)$ by itself does not.

Since (R) brings out the epistemic commitments of realism in this way, I prefer to state the realist account of acceptance in terms of evidential support as 
(R) does instead of permissible belief as $\left(\mathrm{R}^{*}\right)$ does. That being said, nothing in what follows turns crucially on this, so those who reject (B) may safely replace (R) with $\left(\mathrm{R}^{*}\right)$ in what follows and modify the discussion accordingly.

\section{ReCONSTRUCTED EMPIRICISM}

So far I have argued that realism about acceptance ought to be understood as a commitment to (R), which says that one should only accept theories that are supported by the available evidence. It follows that an anti-realist will deny $(\mathrm{R})$, i.e. claim that one may accept a theory whose truth is not supported by the available evidence. Such rejection of $(\mathrm{R})$, however, leaves open whether there is nevertheless some other evidential requirement on accepted theories. So there will be many ways to be an anti-realist. This section examines an anti-realist position which, like van Fraassen's constructive empiricism, replaces the realist's truth with empirical adequacy. ${ }^{14}$ Indeed, since this anti-realist position is closely related to van Fraassen's anti-realism, it may be seen as a modest modification of his constructive empiricism.

Now, we have already seen why, given the Cohen-Dicken distinction, acceptance of a theory need not involve the belief that the theory is empirically adequate. However, in much the same way as realism can be redefined as positing a normative connection between acceptance of a theory and the belief that the theory is true, empiricism may be redefined as positing a normative connection between acceptance of a theory and the belief that the theory is empirically adequate. My suggestion is that empiricism about acceptance should be seen as holding that it is permissible to accept a theory only if it is permissible to believe that it is empirically adequate. Put differently:

$\left(\mathrm{E}^{*}\right)$ A theory $T$ should only be accepted in a scientific context if it is permissible to believe that $T$ is empirically adequate.

\footnotetext{
${ }^{14}$ This choice will be vindicated in the next section, where the relevance of empirical adequacy in this regard will be defended against an objection.
} 
Note, however, that $\left(\mathrm{R}^{*}\right)$ entails $\left(\mathrm{E}^{*}\right)$, so committing to $\left(\mathrm{E}^{*}\right)$ does not by itself make one an anti-realist empiricist of the kind we are attempting to define. Rather, this kind of anti-realist empiricism must be seen as committing to $\left(\mathrm{E}^{*}\right)$ being the whole story about what acceptability requires in terms of permissible belief. So the redefined empiricist view - which I'll call reconstructed empiricism - commits to $\left(\mathrm{E}^{*}\right)$ and rejects any stronger norm, such as $\left(\mathrm{R}^{*}\right)$, relating acceptance and belief.

Now, in the same way that $\left(\mathrm{R}^{*}\right)$ captures the kernel of truth behind the realist view of acceptance defined by van Fraassen, $\left(E^{*}\right)$ captures the kernel of truth in van Fraassen's own empiricist position. For note that if accepting a theory $T$ did involve believing that $T$ is empirically adequate, then surely one should only accept $T$ if it is permissible to believe that $T$ is empirically adequate. Given this conditional, van Fraassen's conception of realism straightforwardly implies $\left(\mathrm{E}^{*}\right)$. As before, the implication does not go the other way however, since one could commit to the claim that one should only accept what it's permissible to believe is empirically adequate, and yet deny in the same voice that one's acceptance of $T$ entails that one believes that $T$ is empirically adequate. So, in sum, reconstructed empiricism is a more modest conception of empiricism which nevertheless captures van Fraassen's basic idea that empiricism posits a connection between acceptance of a theory and the belief in that it is empirically adequate.

Indeed, it may be worth noting that $\left(\mathrm{E}^{*}\right)$ is congenial to van Fraassen's (1989; 2000; 2002; 2007) "voluntarist" epistemology, which emphasizes that rationality is a matter of permission rather than obligation. ${ }^{15}$ Specifically, van Fraassen holds that "we are rational in believing something exactly when we are not rationally compelled to believe the opposite," which he takes to imply that "any truly coherent position is rational" (van Fraassen, 2000, 277). Thus, for van Fraassen,

\footnotetext{
${ }^{15}$ Van Fraassen's voluntarist epistemology should not to be confused with the more familiar thesis of doxastic voluntarism, which is the view that beliefs can be voluntarily adopted. The latter is of course a thesis that we have come across earlier in this essay in discussing the difference between acceptance and belief (see especially footnotes 6 and 11).
} 
there is no single set of beliefs that an agent with some particular evidence is obligated to adopt - rather, she is permitted to accept any coherent set of beliefs. Since $\left(\mathrm{E}^{*}\right)$ refers to what is permissible rather than obligatory for an agent to believe, it can effortlessly accommodate this epistemic voluntarist strain in van Fraassen's thought. ${ }^{16}$ On the other hand, it is also worth emphasizing that this coupling of $\left(E^{*}\right)$ with a van Fraassen-style voluntarist epistemology is entirely optional. Instead of following van Fraassen in taking formal coherence to be the only constraint on permissible beliefs, we may instead take a more traditional route on which there are more substantive epistemic requirements as well. So while $\left(\mathrm{E}^{*}\right)$ is congenial to a voluntarist epistemology, it is also compatible with more mainstream approaches in epistemology. ${ }^{17}$

At any rate, let us also note that given the principle (B) from the previous section, $\left(\mathrm{E}^{*}\right)$ is equivalent to the claim that one should only accept a theory $T$ if one's evidence supports $T$ 's empirical adequacy. ${ }^{18}$ This enables us to define reconstructed empiricism in terms of the following norm which corresponds to the realist's $(\mathrm{R})$ :

(E) A theory $T$ should only be accepted in a scientific context if $T$ 's empirical adequacy is supported by the available evidence.

(E) says, in other words, that a theory $T$ should only be accepted if the available evidence supports that $T$ is correct in all its claims about the observable aspects of the world. For analogous reasons as those concerning $\left(R^{*}\right)$ and $(R)$, I prefer to formulate reconstructed empiricism in terms of $(\mathrm{E})$ instead of $\left(\mathrm{E}^{*}\right)$. Thus, from now on, I shall take reconstructed empiricism to consist in affirming (E)

\footnotetext{
${ }^{16} \mathrm{I}$ am thankful to an anonymous reviewer for encouraging me to explore this connection explicitly here.

${ }^{17}$ This should not be surprising, since as Psillos $(2007,135)$ points out, van Fraassen's voluntarist view in epistemology is quite independent from his empiricist view of scientific acceptance.

${ }^{18}$ Of course, (B) refers to the truth of $p$ and not its empirical adequacy, so one may wonder how (B) says anything relevant to $\left(\mathrm{E}^{*}\right)$. However, for our purposes, to say that $T$ is empirically adequate is equivalent to saying that there is a theory, call it $E(T)$, which holds that $T$ is empirically adequate. Since this theory is true just in case $T$ is empirically adequate, (B) may be used to derive $(E)$ from $\left(E^{*}\right)$. (Another way to derive $(E)$ from $\left(E^{*}\right.$ ) would of course be to appeal to a modified version of (B) which replaces "truth" with "empirical adequacy".)
} 
and rejecting any stronger norm relating acceptance and evidential support. ${ }^{19}$

Two clarificatory points similar to those made about (R) apply to (E) as well. First, (E) is similar to (R) and (B) in that it should be understood as positing a pro tanto obligation that may be outweighed or overridden in particular cases, e.g. by moral or prudential considerations. Second, and relatedly, (E) is certainly compatible with there being other normative requirements on acceptance besides (E), such as pragmatic requirements to accept as simple and well-managed theories as possible. Indeed, as van Fraassen notes, empiricists (and anti-realists more generally) will tend to make more of the pragmatic aspects of acceptance due to the fact that empirical adequacy is weaker than truth. (van Fraassen, 1980, 13) This is true of (E) as well since pragmatic features of a theory must be appealed to in deciding which theory to accept in a set of theories that make identical (or equally well supported) claims about observable aspects of the world.

Where does this leave us vis-à-vis the objection that constructive empiricism is confused in virtue of acceptance collapsing into belief (Blackburn, 1984, 2002; Melchert, 1985; Mitchell, 1988; Horwich, 1991) or vice versa (Teller, 2001)? Well, recall that while distinguishing acceptance and belief in the manner of Cohen (1992) and Dicken (2010) dispels the worry that the debate is confused or trivially settled in favor of the realist, it landed us in the awkward position of having to say that realism and constructive empiricism are both false in virtue of the obvious fact that it is possible to adopt a policy of using a theory for various purposes even though one does not feel that it is true. What we now see is that this difficulty can be overcome by modifying both positions so as to concern the normative connection between acceptance and permissible belief and/or evidential support. Thus modified, an empiricist position - reconstructed empiricism - is not ruled out as confused or trivially false in virtue of conceptual truths about belief and

\footnotetext{
${ }^{19}$ As before, nothing in what follows turns crucially on this, so those who reject (B) may safely replace $(\mathrm{E})$ with $\left(\mathrm{E}^{*}\right)$ in what follows and modify the discussion accordingly.
} 
acceptance. $^{20}$

\section{The Relevance of Empirical Adequacy}

The previous section proposed a reconstructed empiricist position in the style of van Fraassen's constructive empiricism, and argued that such a reconstruction avoids the objections of Blackburn, Melchert, Mitchell, Horwich, and Teller. This section argues for a further advantage of this way of reconstructing empiricism about acceptance, viz. that it undergirds the relevance of the distinction between observable and unobservable entities (and the related distinction between empirically adequate and inadequate theories). Accordingly, it serves the basis for an empiricist reply to the objection, commonly made against constructive empiricism, that the notions of observability and empirical adequacy are somehow arbitrary or insignificant and that an empiricist position that relies on them is thus unmotivated.

\subsection{The Manifestationalist Challenge}

A common challenge to van Fraassen's constructive empiricism targets its reliance on the distinction between observable and unobservable aspects of the world (and the related distinction between empirically adequate and inadequate theories). Before we examine the challenge, however, let us first note that van Fraassen himself acknowledges that the boundary between what's observable and unobservable is vague and relative to the epistemic community in which scientists are working. (van Fraassen, 1980, 1985) Indeed, for van Fraassen, what's observable is itself a matter of empirical investigation, and thus there is no simple rule

\footnotetext{
${ }^{20}$ Of course, the corresponding realist position is not ruled out either. Indeed, as advertised in section 1, this paper contains no direct positive arguments for reconstructed empiricism as against the corresponding realist position. However, having shown that an empiricist position about acceptance is not (contra Blackburn, Melchert, Mitchell, Horwich, and Teller) incoherent or confused, we can conclude that one may be an empiricist about acceptance, should one be so inclined, and that realism about acceptance is not "the only game in town".
} 
for telling what counts as observable or unobservable. Yet, van Fraassen argues, the fact that a distinction is vague, relative, and not yet fully specified does not mean that one cannot employ it in one's philosophical theorizing about science. (Muller and van Fraassen, 2008; van Fraassen, 2001)

Van Fraassen may very well be correct to dismiss concerns about how and where to draw the distinction between observable and unobservable entities. The deeper worry in the vicinity, however, is not that the distinction cannot be coherently drawn, but that the significance that the empiricist attributes to it is unmotivated. The worry, in short, is that the observability-distinction is of no epistemic significance in science and thus cannot bear the weight that constructive empiricism puts on its shoulders. In support of this, realists often point out that it is hard to see what is in principle more problematic about forming beliefs concerning unobservable entities than forming beliefs about unobservedbut-observable entities. Why, for example, would it be more problematic for scientists to confirm that there are unobservable atoms than that there is some observable-but-as-yet-unobserved deep sea creature? More generally, it seems that if empiricists are worried about the epistemic support one could acquire for believing theories concerning unobservable entities, they ought to worry equally about theories concerning unobserved-but-observable entities. (Railton, 1989; Rosen, 1994; Sober, 1985, 1993; Churchland, 1985; Psillos, 1996; Alspector-Kelly, 2001; Kitcher, 2001; Ladyman, 2007)

This general problem may seem to undermine reconstructed empiricism just as much as constructive empiricism, since both positions appeal to the notion of empirical adequacy, thus relying on the distinction between observable and unobservable aspects of the world. More specifically, the worry would be that any epistemic motivation for (E) in fact provides a stronger motivation for an even weaker connection between acceptance and evidential support:

(M) A theory $T$ should only be accepted in a scientific context if T's manifestation adequacy is supported by the available evidence.

where a theory is "manifestationally adequate" just in case it is correct in all its 
claims about what has been observed so far. (Railton, 1989) Note again that (M) does not by itself conflict with $(\mathrm{E})$ or $(\mathrm{R})$, so this more extreme anti-realist view - which I'll call manifestationalism - must be understood as claiming that (M) is the whole story about the normative relationship between acceptance and evidential support, i.e. that all stronger norms of this sort are false.

The problem this poses for the reconstructed empiricist is that her position looks to be unstable in that the epistemic modesty which is taken to motivate the position in fact leads to an even more extreme anti-realist position, viz. manifestationalism. Call this the manifestationalist challenge. Of course, this challenge is exactly analogous to the objection made against van Fraassen's constructive empiricism, so it may seem that reconstructed empiricism is in no better shape than constructive empiricism in this regard. However, in what remains of this section, I show that reconstructed empiricism has a convincing answer to the manifestationalist challenge, roughly because of the role accepted theories play in empirical predictions.

\subsection{Empirical Adequacy and Prediction}

Recall that on Cohen and Dicken's definition, accepting a theory in a scientific context amounts to treating that theory as given for various scientific purposes. Now, one purpose of having scientific theories at all - emphasized in particular by many empiricists - is to enable us to make predictions about the behavior of the observable world, i.e. empirical predictions. (Here, "prediction" should be understood in a broad sense that includes predictions about the the present and the past ("retrodictions"), since scientific theories are also used to make predictions of this sort.) Given this, it looks to be part of what it is to accept a scientific theory that one uses it as a basis for empirical predictions. ${ }^{21}$ More

\footnotetext{
${ }^{21}$ A similar points was made by Nancy Cartwright in a recent sympathetic discussion of van Fraassen's position: "To accept a theory is to decide to use it to make all those predictions about what we might observe that will help us chart our actions." (Cartwright, 2007, 40)
} 
precisely, acceptance in a scientific context involves having a policy of treating that theory as given for the purposes of empirical predictions, so that the theory may be called upon (often in conjunction with other theories, as the DuhemQuine thesis teaches us) to help us predict what we would come to observe in a given situation (past, present, or future).

To be clear, I am not claiming that scientific acceptance involves nothing other than having a policy of treating a theory as given in empirical predictions, only that this is part of what acceptance involves. Plausibly, one does not accept a theory - at least not fully - unless one is also treats it as given for other scientific purposes, e.g. in explanations and in guiding further theory construction. ${ }^{22}$ It is also worth clarifying that since we are concerned with full as opposed to partial acceptance here (see section 2), it follows that in so far as acceptance of a theory involves having a policy of treating it as given in empirical predictions, full acceptance involves having a policy of treating it as given in any given empirical prediction. Partial acceptance, by contrast, is consistent with only treating the theory as given for the purposes of some predictions, e.g. as Newtonian mechanics is often used as an approximation to General Relativity (but only when velocities do not approach the speed of light).

So to accept a theory in a scientific context involves having a policy of taking that theory as given for the purposes of empirical predictions. This basic point serves as the basis for a reply on behalf of reconstructed empiricism to the manifestationalist challenge posed above. To see this, note first that according to manifestationalism one may accept a theory, and hence treat it as given for the purposes of empirical predictions, as long as its manifestational adequacy is supported by the available evidence. However, a manifestationally adequate group of theories may make radically incorrect empirical predictions about unobserved phenomena - after all, manifestationally adequate theories need only be correct

\footnotetext{
${ }^{22}$ Here I am disagreeing with what seems to be Cartwright's position in the quote in the previous footnote, where she seems to suggest that acceptance of a theory involves nothing other than using the theory to make empirical predictions.
} 
about what has been observed so far. So manifestationalism implies that scientists may treat a theory as given for the purposes of empirical predictions even if they have no evidence to support that the predictions of that theory about unobserved phenomena will be correct.

The situation is very different for reconstructed empiricism. To see this, note that there is an intimate relationship between empirical predictions and empirical adequacy: The empirical predictions made by a group of theories will all be correct only if the theories in question are empirically adequate. Of course, an empirically inadequate group of theories may make some correct empirical predictions, but the predictions will not all be correct unless the theories are empirically adequate. So empirical adequacy is precisely that relation between theory and world which ensures that a given theory (or group of theories) makes only correct empirical predictions. It follows that reconstructed empiricism's (E) in effect states that theories should only be accepted, and hence be treated as given for the purposes of empirical predictions, if the correctness of those empirical predictions is supported by the available evidence.

Manifestationalism and reconstructed empiricism thus disagree about the normative requirement on scientists qua empirical predictors. In particular, manifestationalist affirms, while reconstructed empiricism denies, that theories may be treated as given in empirical predictions in science even if there is no evidence which supports that its empirical predictions about unobserved phenomena are correct. From the standpoint of those who take science to be, in van Fraassen's words, "paradigm of rational inquiry" (van Fraassen, 1994, 192), the reconstructed empiricist's stance on this issue is clearly preferable to manifestationalism's. From this point of view, manifestationalism cannot make sense of the role played by accepted theories in empirical predications, since it entails that scientists are under no obligation whatsoever to make predictions about unobserved phenomena whose correctness is supported by the available evidence. Reconstructed empiricism, by contrast, can make sense of the role of accepted theories in empirical predictions about unobserved as well as observed phenom- 
ena while at the same time respecting a commitment to the rationality of science, since it entails that scientists are obliged not to treat theories as given in empirical predictions unless they have reason to believe that the predictions in question will be correct.

In sum, then, reconstructed empiricism can give a principled reason why empirical adequacy - and thus observability - is relevant for acceptance, viz. that empirical adequacy is precisely what is required of accepted theories in order for them to make only correct empirical predictions. It is worth noting that this motivation comes not from the observability distinction marking some important epistemological distinction such that all and only things falling on one side of the distinction can be supported by empirical evidence. Rather, the relevance of the distinction comes from facts about what it is to accept a theory in a scientific context, viz. that such acceptance involves using the theory as a basis for empirical predictions. Thus, contrary to what is often suggested by realists, the observability distinction is motivated not by an epistemological principle about what can and cannot be known or reasonably believed, but rather by the use to which theories are put in the scientific enterprise. ${ }^{23}$

\section{Conclusion}

We started with a conception of scientific realism proposed by van Fraassen (1980), one according to which a realist holds that a belief that $T$ is true is necessary for acceptance of $T$, while an empiricist holds that only belief in $T$ 's empirical adequacy is necessary for acceptance of $T$. However, we saw that if

\footnotetext{
${ }^{23}$ It may be worth adding that the points made in this section about the relationship between acceptance, empirical predictions, and empirical adequacy do not also provide a rationale for the relevance of empirical adequacy in van Fraassen's constructive empiricism. To see this, note that even if accepting a theory involves using it in empirical predictions, which in turn are all correct only if the theory is empirically adequate, it does not follow that any belief in the theory's empirical adequacy is involved in acceptance. After all, it is clearly possible to use a theory in empirical predictions even if one does not feel it to be true that the theory is empirically adequate. (Alyssa from section 2 is a case in point.) So even if acceptance involved using a theory in empirical predictions, which in turn are all correct just in case the theory is empirically adequate, it would not follow that acceptance involves belief in the theory's empirical adequacy.
} 
we adopt a plausible story about how to distinguish between "acceptance" and "belief" (and we need some such story on pain of trivializing the debate, as the arguments of Blackburn, Melchert, Mitchell, Horwich, and Teller show), then it turns out that acceptance does not require either kind of belief. Accordingly, I suggested that realism and its competitors should be conceived of as theses about the normative connection between acceptance and belief. In this spirit, I proposed an empiricist view in the spirit of van Fraassen's constructive empiricism, and showed that it is immune to the objection that acceptance collapses into belief.

Furthermore, this empiricist position turns out to enable us to make sense of the empiricist's emphasis on the distinction between observable and unobservable entities and thus avoid what I called the manifestationalist challenge. The observability distinction turns out to be relevant in virtue of a the role played by accepted theories in empirical predictions, and the relationship between empirical predictions and empirical adequacy. This dispels an important and influential objection to empiricist views in the scientific realism debate, viz. that the observability distinction is arbitrary or unmotivated. I thus conclude that a reconstructed empiricist position, construed as positing a normative connection between acceptance and empirical adequacy, avoids two of the most serious challenges to an empiricist view of scientific acceptance. ${ }^{24}$

\section{REFERENCES}

Alspector-Kelly, M. (2001). Should the Empiricist be a Constructive Empiricist?

Philosophy of Science, 68:413-433.

\footnotetext{
${ }^{24}$ I would like to thank Marc Lange, John Roberts, Matt Kotzen, and Lindsay Brainard for very helpful comments on drafts of this paper. Versions of this paper were presented at the University of North Carolina Work-in-Progress series in 2013, the North Carolina Philosophical Society Annual Meeting in 2014, and the 15th Congress of Logic, Methodology and Philosophy of Science at the University of Helsinki in 2015. I am grateful to members of the audience on all three occasions for their questions and comments.
} 
Alston, W. (1996). Belief, Acceptance, and Religious Faith. In Jordan, J. and Howard-Snyder, D., editors, Faith, Freedom, and Rationality. Rowman \& Littlefield, Lanham, MD.

Blackburn, S. (1984). Spreading The Word. Clarendon, Oxford.

Blackburn, S. (2002). Realism: Deconstructing the Debate. Ratio (new series), 15:111-133.

Bratman, M. (1992). Practical Reasoning and Acceptance in a Context. Mind, 401:1-16.

Cartwright, N. (2007). Why Be Hanged for Even a Lamb? In Monton, B., editor, Images of Empiricism: Essays on Science and Stances, with a Reply from Bas C. van Fraassen, pages 32-45. Oxford University Press, Oxford.

Churchland, P. M. (1985). The Ontological Status of Observables: In Praise of the Superempirical Virtues. In Churchland, P. M. and Hooker, C. A., editors, Images of Science, pages 35-48. University of Chicago Press.

Cohen, L. J. (1989). Belief and Acceptance. Mind, 93:367-389.

Cohen, L. J. (1992). An Essay on Belief and Acceptance. Clarendon Press, Oxford.

Dicken, P. (2010). Constructive Empiricism: Epistemology and the Philosophy of Science. Palgrave Macmillan, New York.

Duhem, P. (1954/1982). The Aim and Structure of Physical Theory. Princeton University Press, Princeton, NJ.

Horwich, P. (1991). On the Nature and Norms of Theoretical Commitment. Philosophy of Science, 58:1-14.

Kaplan, M. (1981a). A Bayesian Theory of Rational Acceptance. Journal of Philosophy, 78:305-330.

Kaplan, M. (1981b). Rational Acceptance. Philosophical Studies, 40:129-145. 
Kaplan, M. (1995). Believing the Improbable. Philosophical Studies, 77:117-146.

Kitcher, P. (2001). Real Realism: The Galilean Strategy. The Philosophical Review, 110:151-197.

Ladyman, J. (2007). The Epistemology of Constructive Empiricism. In Monton, B., editor, Images of Empiricism: Essays on Science and Stances, with a Reply from Bas C. van Fraassen, pages 46-61. Oxford University Press, Oxford.

Lance, M. N. (1995). Subjective Probability and Acceptance. Philosophical Studies.

Lehrer, K. (1979). The Gettier Problem and the Analysis of Knowledge. In Pappas, G. S., editor, Justification and Knowledge, pages 65-78. D. Reidel Publishing Company.

Maher, P. (1993). Betting on Theories. Cambridge University Press, Cambridge.

Melchert, N. (1985). Why Constructive Empiricism Collapses into Scientific Realism. Australasian Journal of Philosophy, 63:213-215.

Mitchell, S. (1988). Constructive Empiricism and Anti-Realism. In PSA 1988: Proceedings of the Biennial Meeting of the Philosophy of Science Association, volume 1 , pages $174-180$.

Muller, F. and van Fraassen, B. C. (2008). How to Talk about Unobservables. Analysis, 68:197-205.

Pearson, K. (1911). The Grammar of Science, 3rd edition. Macmillan, New York, NY.

Psillos, S. (1996). On Van Fraassen's Critique of Abductive Reasoning. The Philosophical Quarterly, 46:31-47.

Psillos, S. (2007). Putting a Bridle on Irrationality: An Appraisal of van Fraassen's New Epistemology. In Monton, B., editor, Images of Empiricism: Essays on Science and Stances, with a Reply from Bas C. van Fraassen, pages 134-164. Oxford University Press, Oxford. 
Railton, P. (1989). Explanation and Metaphysical Controversy. In Kitcher, P. and Salmon, W. C., editors, Minnesota Studies in the Philosophy of Science, vol. 13, pages 220-252. University of Minnesota Press.

Rosen, G. (1994). What is constructive empiricism? Philosophical Studies, 74:143-178.

Sober, E. (1985). Constructive Empiricism and the Problem of Aboutness. British Journal for the Philosophy of Science, 36:11-18.

Sober, E. (1993). Epistemology for Empiricists. Midwest Studies in Philosophy, 18:39-61.

Teller, P. (2001). Whither Constructive Empiricism. Philosophical Studies, 106:123-150.

van Fraassen, B. C. (1980). The Scientific Image. Clarendon, Oxford.

van Fraassen, B. C. (1985). Empiricism in the Philosophy of Science. In Churchland, P. M. and Hooker, C. A., editors, Images of Science. Chicago University Press, Chicago, IL.

van Fraassen, B. C. (1989). Laws and Symmetry. Clarendon Press, Oxford.

van Fraassen, B. C. (1994). Gideon Rosen on Constructive Empiricism. Philosophical Studies, 74:179-192.

van Fraassen, B. C. (2000). The False Hopes of Traditional Epistemology. Philosophy and Phenomenological Research, 60:253-280.

van Fraassen, B. C. (2001). Constructive Empiricism Now. Philosophical Studies, 106:151-170.

van Fraassen, B. C. (2002). The Empirical Stance. Yale University Press, New Haven.

van Fraassen, B. C. (2007). From a View of Science to a New Empiricism. In Monton, B., editor, Images of Empiricism: Essays on Science and Stances, 
with a Reply from Bas C. van Fraassen, pages 337-385. Oxford University Press, Oxford.

Velleman, J. D. (2000). On the Aim of Belief. In The Possibility of Practical Reason, pages 244-281. Oxford University Press, Oxford.

Williams, B. (1973). Deciding to believe. In Problems of the Self, pages 136-151. Cambridge University Press, Cambridge. 